\title{
Cognitive and affective components of stimuli presented in three modes
}

\author{
PATRICIA B. HINTON \\ University of Tennessee, Knoxville, Tennessee \\ and \\ TRACY B. HENLEY \\ Mississippi State University, Mississippi State, Mississippi
}

(B. Michael Thorne, Sponsor)

\begin{abstract}
This study was conducted to compare responses to stimuli presented in three different modalities: olfactory, visual, and lexical (the written name of the object). Cognitive aspects of these responses as well as affective components were examined. The subjects were placed at random into one of three experimental groups and were tested individually. Each subject was asked to smell, to view, or to see the name of six common items and to write whatever immediately came to mind after each stimulus presentation. The results indicate that the olfactory mode produced the shortest answers, with the largest amount of affect. The results are discussed in terms of their implications about the structure and nature of concepts and how such concepts interrelate with different sensory modalities.
\end{abstract}

Marcel Proust wrote in Remembrance of Things Past, "When from a long-distant past nothing subsists, after the people are dead ... taste and smell alone ... remain poised a long time, like souls, remembering, waiting, hoping, amid the ruins of all the rest; and bear unflinchingly ... the vast structure of recollection."

This "vast structure of recollection," especially in its different sensory states, was the backdrop of the present investigation. Of specific interest was the idea that different perceptual domains (e.g., vision, olfaction) may have different types of underlying schemata, an idea that has been previously suggested by some (e.g., Brewer \& Nakamura, 1984). Indirect evidence for this possibility exists, although no empirical work has hitherto been done to examine it directly (see, e.g., Lyman \& McDaniel, 1986, 1990). The purpose of the present research was to explore in a preliminary way whether the structures of memory and language (taken to be a manifestation of underlying schemata) have different features based on the sensory modality involved in the original encoding experience.

We were particularly interested in olfaction and responses cued by olfaction as opposed to visual and lexical cues of the same stimulus. It has been suggested that olfaction is structurally and functionally at the heart of remembering and emotion (e.g., Almagor, 1990; Engen, 1987, 1991; Gibbons, 1986; Gilbert \& Wysocki, 1987), yet little is known about the "cognitive" aspects of olfaction. The present hypothesis was that associations cued

Correspondence should be sent to T. B. Henley, Department of Psychology, Mississippi State University, Mississippi State, MS 39762-6161 (e-mail: tbh1@ra.msstate.edu). by olfactory and visual modes of the same stimulus would produce both qualitatively and quantitatively different responses from subjects. This hypothesis was based on research that suggests that unlike visual or auditory stimuli, odors lack distinct features, and we sometimes stumble in identifying even familiar ones (Engen, 1991; see also Gibbons, 1986; Rabin \& Cain, 1984).

In summary, we expected to find significant differences in both the quality and the quantity of memories and associations produced by presenting stimuli in different sensory modes. The affect elicited by presentation in the olfactory mode was expected to be greater, and the other modes were expected to elicit longer responses, because of the probably nonlexical nature of olfactory encoding (Engen, 1987). Such results could be taken as very preliminary evidence for the viability of different schematic structures representing concepts encoded via different sensory modalities.

\section{METHOD}

\begin{abstract}
Subjects
The subjects for this study were 19 male and 36 female undergraduate psychology students from both day and evening classes at the University of Tennessee, Knoxville. Participation was voluntary and extra credit points were given. The volunteers were screened with a questionnaire on the consent form for allergies and for any olfactory or visual deficit that might introduce a confound.

The subjects were randomly assigned to one of three experimental groups, with 19 subjects in the olfactory condition, 18 in the visual condition, and 18 in the lexical (word) condition.
\end{abstract}

\section{Materials}

All subjects were exposed to the same six items: freshly brewed coffee (see the protocol below for the presentation method), freshly cut car- 
nations, recently cut pine boughs, tobacco from a popular brand of filterless cigarette (Camels), a Florida navel orange, and an unwrapped bar of scented soap (Ivory). These items were chosen for their distinctive aroma as well as for their everyday familiarity (Cain, 1981).

Each subject was given six pieces of standard white paper, numbered one through six, on which to record responses.

\section{Procedure}

All subjects were tested individually. They were told that six common everyday items or item names would be presented, one at a time. They were asked to write whatever immediately came to mind when the stimulus was presented. It was emphasized that there was no time limit, no right or wrong response, and no correct length of response. It was then repeated that they should write whatever first came to mind when the stimulus was presented. The subjects were asked to turn to the next sheet of paper to signal the experimenter to present the next stimulus.

The stimuli were presented one at a time, in random order. The word stimuli were clearly and neatly written in black marker on individual sheets of plain, white $8.5 \times 11$ in. $(21.5 \times 28 \mathrm{~cm})$ cardstock. The names were as follows: Coffee, Oranges (plural to distinguish from the color orange), Tobacco, Carnations, Pine tree branch, and Ivory soap. The stimulus card was held approximately $2.5 \mathrm{~m}$ from the viewing subject for as long as the subject needed to view it.

In the visual condition, the actual items were brought into the experimental room one at a time. They were held approximately $300 \mathrm{~cm}$ from the subject for approximately $10 \mathrm{sec}$ and were moved when the subject began writing. The experimenter presented the coffee by walking in with a pot of cold coffee (to control for odor) and pouring out a cup at eye level. (A pilot run of the experiment showed that black liquid in a cup could be construed as one of several liquids, so the procedure was modified to include pouring from a carafe in view of the subject.) To present the cigarette tobacco, the experimenter walked in with the cigarette held in the palm of the hand at a level where the seated subject could see it from a distance of about $300 \mathrm{~cm}$. Pilot studies indicated that $300 \mathrm{~cm}$ was an appropriate visual distance to control for the odors of the stimulus materials as they were presented.

In the olfactory condition, the stimulus materials were presented in the following manner. The subject was seated in a swivel chair in the experimental room with his/her back to the door and to the experimenter On a small table directly behind the subject was a cardboard box, measuring $23 \times 31 \times 36 \mathrm{~cm}$, with the open side facing the experimenter. A $15-\mathrm{cm}$ circle was cut in the edge of the box facing the subject and was covered with visually opaque cheesecloth. Each stimulus was brought in and placed in the box near the cheesecloth-covered opening, and the subject was then asked to swivel around and place his/her nose near the cheesecloth and inhale deeply two or three times. It was emphasized that this was not an odor identification task and that we were interested in whatever thoughts first came to mind after the subject inhaled the aroma. If the subject could not detect any aroma after a few attempts, the subject was asked to write "no response" and go on to the next stimulus. It must be emphasized that we used olfactory items in their natural state, as they occur in the world, rather than artifical chemical odors, in order to preserve the ecological validity of these findings.

On the basis of pilot work, it was found that the best presentation of the pine branch stimulus was to place it inside the covered box in the bag in which it was stored. The bag was opened immediately before the branch was placed in the stimulus box. Several cuts had been made earlier in the branch's bark, to intensify the odor in the bag. Similarly, the navel orange was scored with a knife and slightly squeezed before it was brought into the experimental room. The cigarette stimulus was cut into small pieces and presented in a small ceramic container underneath the cheesecloth opening. The soap was presented unwrapped on a plain piece of cardboard held below the cheesecloth. After several pilot runs, it was found that the best way to present the carnation stimulus was to cut a fresh carnation (fresh for each subject) into several pieces. These were placed on a piece of cardboard held below the cheesecloth opening. The coffee was presented in an open carafe inside the experimental box.

\section{RESULTS}

The number of words for each response was counted, number of words being one way to gauge the complexity and content of responses. Items with "no reponse" received a word count of zero. An affect value score was obtained by having 3 student raters score each response on a scale of $0-3$. The raters were told that 0 represented no affect present in the response, 1 represented little affect, 2 represented moderate affect, and 3 represented large or strong affect. No attempt was made to train the raters regarding the amount of affect. Since the perceived affect of experiences is variable, perfect reliability was not an objective here (though agreement was reasonable at about .7). After the three ratings for each response had been obtained, these values were averaged for each response in all conditions to provide a normalized measure.

There were significant differences in the overall length of response depending on modality, with olfaction producing the shortest responses and visual stimuli producing the longest responses $\left[\chi^{2}(6,330)=25.41, p=.001\right]$. This simple relationship is somewhat misleading, however, because the olfactory responses tended to be either very long or very short. There was a correlation between length of response and affect $(r=.55, p<.0001)$; however, it should be noted that it is hard to capture strong affect in just one or two words. There were no significant differences across the six stimuli in the length of response within any of the modalities. For other statistical purposes, word counts were divided into quartiles and coded, with responses containing $<11$ words as Quartile 1; 11-23 words, Quartile 2; 24-41 words, Quartile 3; and 42-122 words, Quartile 4. There was a significant sex difference in length of response, with males in our sample producing more responses in the fourth quartile (42- to 122-word range) $\left[\chi^{2}(3,330)=9.97, p<.02\right]$.

A look at the affect rating across all stimuli shows that significantly more responses in the olfactory mode were rated 3 , strong affect, or 0 , no affect, whereas $81 \%$ of the responses in the visual mode had a rating of either 1 or $2\left[\chi^{2}(6,330)=25.41, p<.0001\right]$. The subjects' gender was not found to be a significant factor in affect. There were significant differences in affect rating of stimuli across modalities, with tobacco having the highest affect rating $\left[\chi^{2}(15,330)=46.92, p<.001\right]$.

A qualitative look at the descriptors and response content shows that the subjects in the olfactory condition frequently had a difficult time describing what they smelled. They often responded that they recognized the odor or found it familiar but could not identify it. For example, in smelling the orange stimulus, a subject responded, "Citrus. Not a lemon or lime. Sweet." Another said of the same stimulus, "I smelled a citrus smell that seemed to be an orange." This element of tentativeness in odor identification was frequently present. The adjectives used usually signified the smell itself rather than other attributes of the stimulus. In contrast, the visual mode of the 
Table 1

Stimulus: Oranges

Sample Attributes/Adjectives Elicited

\begin{tabular}{lll}
\hline \multicolumn{1}{c}{ Olfactory } & \multicolumn{1}{c}{ Visual } & \multicolumn{1}{c}{ Word } \\
\hline citrus & round shape & Florida \\
sweet & orange color & vitamin C \\
familiar & Florida & juicy \\
sour & healthy & round shape \\
good & vitamin C & seeds \\
warmth & good for you & orange color \\
clean & pulp & sweet \\
fresh & slimey & sticky \\
great & tastes good & school color \\
refreshing & school color & Valencia \\
juicy & basketball & TV commercials \\
smells like Florida & sunshine & Minute Maid \\
\hline
\end{tabular}

same stimulus elicited many remarks about the juiciness, taste, texture, shape, and so forth. Responses from the word-stimulus Oranges were arguably more cognitive. They often referred to the health benefits of eating citrus, its vitamin content, its similarity to a basketball in shape and color, and its relation to the university color, which at Tennessee is orange. A comparison of the adjectives for the orange stimulus across modalities from 12 random subjects each is presented in Table 1 as an example of these data.

Table 2 presents a contrast of the types of responses cued by the example stimulus Oranges. The responses cued by olfaction were very personal and had stronger affective components that did the responses cued in the other modalities. Responses in the lexical modality seemed "intellectual" rather than personal. Although it is difficult to quantify these responses, there also seemed to be a pull for "older," less recent memories in the olfactory mode. Data for the other five stimuli followed the pattern illustrated by the sample stimulus Oranges.

\section{DISCUSSION}

The results of this study suggest that responses to olfactory stimuli are both quantitatively and qualitatively different from responses elicited by other sensory modes. On the balance, olfactory responses were shorter than others. This effect could be due to the nonlexical nature of the olfactory coding, as mentioned in the introduction. Also, this nonlexical coding does appear to make olfactory cues very dependent on the original encoding context, leading to some vivid, graphic, and at times lengthier responses than were seen in the other modes.

As for affect, the outcomes were as expected. As predicted, the olfactory mode produced the greatest overall affect rating. Some respondents noted very personal and poignant memories cued by the olfactory stimuli. The strongest (most intense) of the olfactory cues-coffee, orange, and Ivory soap-produced the strongest affect value scores. However, less intense or neutral odors produced less affect than did the other two modes for these particular stimuli. This affect response pattern was identical to Gilbert and Wysocki's (1987) finding that the stronger the odor, the more likely it is to bring to mind a vivid memory or association. Across modalities, it was found that, on the average, the stronger the affective content of each response, the greater the number of words elicited in that response.

One unexpected finding in our analysis was that there was no significant difference between the sexes in the amount of affect in the responses. Gilbert and Wysocki (1987) noted in previous olfactory research that women rate many odors as more intense than male subjects do, and we had anticipated that our female subjects would have more overall affect in the olfactory condition. Likewise, we anticipated that females in the olfactory condition would produce significantly longer answers than would males. In our study, a significantly higher percentage of males as opposed to females produced long responses (Quartile 4) across all modalities. We have no explanation for this finding.

When the responses evoked by the stimuli were closely examined, these memoria, to use Neisser's (1988) term, yielded another feature that crossed all modalities and all stimuli. These autobiographical memories were not usually of some specific event in the past but rather of some expected pattern of events that occurred in the past. Neisser noted that ordinary memory of the past has more to do with meaning and usual patterns of events than with a detailed chronological accounting of each specific remembered event. In cases of unusual landmark events as opposed to ordinary daily events, this does not seem to hold true. In our experiment, the few specific memories that were evoked were of the landmark nature. For instance, one respondent reported that seeing the orange reminded him of a specific Vanderbilt/University of Tennessee football game, at the end of which the fans threw oranges all over the field. However, the typical memory recalled in our study was of the "expected pattern" type, exemplified by "I know what coffee smells like and that is simply final exam time ... sitting in the library trying to keep awake during the last week of finals." A subject smelling the soap responded, "Summer at my lakehouse. Swimming in the lake and bathing at the same time." These were memories of general scripts of how final exam time and summer time were typically experienced by that person.

In summary, this experiment yielded interesting data on the differences in both encoding and recall of information through different sen-

Table 2

Stimulus: Oranges

Verbatim Examples of Responses Elicited

\section{Olfactory Mode}

Smells like Florida. It reminds me of my childhood when I lived in Florida and would go to the orange grove and pick fresh oranges. I could stay there all day. It didn't actually smell great but it did remind me of a time I had forgotten.

This scent reminded me of an earlier time in my life. From the time I can remember to the age of 8 we lived in Cocoa Beach, Florida. Our yard had 4 orange trees and 2 grapefruit trees. We used to go outside in the morning and pick these fruits for our lunch; I also used to come home from playing in the orange groves smelling like this from head to toe.

Makes me think of morning time, eating a big breakfast with my children.

\section{Visual Mode}

First I thought of round objects then the orange color came to my mind and reminded me of the athletic department since I am part of it and it is our school color.

It's an orange. Comes in mesh bags. Don't like oranges . . . Sit on kitchen counter with other fruit, great for kids . . . Try to peel so entire peel stays intact.

Traveling to Florida and while driving seeing all the orange groves on the side of the road.

\section{Word Mode}

Orange the color. The acid smell on hands after peeling, the juice, eating them during track meets, Valencia, mandarin, sunkist.

Round in shape. Same shape as the world. Sweet tasting but sometimes you get a sour one. Color I do not like much.

Of course I think of orange juice. I am in a sorority and one of the girls in my pledge class is named Valencia. So of course everyone calls her $100 \%$ Valencia orange juice. 
sory modalities. The richness of sensory experience could be due to these intrinsically different encoding events, many of which are nonlexical. This may well be due to the nature of schemas-the lexical (facts about things) and the perceptual (sights, sounds, smells, etc.) may not be as intimately connected as has previously been thought. (For similar findings regarding visual memories, see Schooler \& Engstler-Schooler, 1990.) Our subjects experienced memories that yielded richness in meaning, yet they often had difficulty capturing this "vast structure of recollection" in words. This dissociation between language and thought invites further consideration.

\section{REFERENCES}

Almagor, U. (1990). Some thoughts on common scents. Journal for the Theory of Social Behaviour, 20, 181-195.

BreWer, W., \& NaKamura, G. (1984). The nature and function of schemas. In R. Wyer \& T. Srull (Eds.), Handbook of social cognition (Vol. 1, pp. 119-160). Hillsdale, NJ: Erlbaum.

CaIN, W. (1981). Educating your nose. Psychology Today, 7, 48-56.

Engen, T. (1987). Remembering odors and their names. American Scientist, 75, 487-503.

Engen, T. (1991). Odor sensation and memory. New York: Praeger.
GiBBons, B. (1986, September). The intimate sense of smell. National Geographic, pp. 324-370.

GILBERT, A., \& WysockI, C. (1987, October). The smell survey results. National Geographic, pp. 514-525.

LyMAN, B., \& MCDANIEL, M. (1986). Effects of encoding strategy on long-term memory for odours. Quarterly Journal of Experimental Psychology, 38A, 753-765.

Lyman, B., \& MCDANiel, M. (1990). Memory for odors and odor names: Modalities of elaboration and imagery. Journal of Experimental Psychology: Learning, Memory, \& Cognition, 16, 656-664.

NeISSER, U. (1988). What is ordinary memory the memory of? In U. Neisser \& E. Winograd (Eds.), Remembering reconsidered: Ecological and traditional approaches to the study of memory, (pp. 356373). Cambridge: Cambridge University Press.

RABIN, M., \& CAIN, W. (1984). Odor recognition: Familiarity, identifiability, and encoding consistency. Journal of Experimental Psychology: Learning, Memory, \& Cognition, 10, 316-325.

SCHOOLER, J., \& ENGSTLER-SCHOOLER, T. (1990). Verbal overshadowing of visual memories: Some things are better left unsaid. Cognitive Psychology, 22, 36-71.

(Manuscript received June 30, 1993.) 